\title{
Double-balloon enteroscopy for ERCP in patients with Billroth II anatomy: results of a large series of papillary large-balloon dilation for biliary stone removal
}

Authors

Institutions
Chi-Liang Cheng ${ }^{1}$, Nai-Jen Liu', Jui-Hsiang Tang ${ }^{1}$, Ming-Chin Yu², Yi-Ning Tsui ${ }^{1}$, Fang-Yu Hsu' ${ }^{1}$, Ching-Song Lee ${ }^{1}$, Cheng-Hui Lin

Institutions are listed at the end of article. submitted

12. September 2014 accepted after revision

7. January 2015

\section{Bibliography}

DOI http://dx.doi.org/

10.1055/s-0034-1391480

Published online: 6.5.2015

Endosc Int Open 2015; 03:

E216-E222

(c) Georg Thieme Verlag KG

Stuttgart · New York

E-ISSN 2196-9736

Corresponding author

Cheng-Hui Lin, MD

Division of Gastroenterology Department of Medicine

Chang Gung Memorial Hospital

5 Fu-Hsin Road, Queishan

Taoyuan 333

Taiwan

Fax: +886-3-4630150

linchehui@adm.cgmh.org.tw
Background and study aims: Data on double-balloon enteroscopy (DBE)-assisted endoscopic retrograde cholangiopancreatogrphy (ERCP) in patients with Billroth II gastrectomy and the use of endoscopic papillary large-balloon dilation (EPLBD) for the removal of common bile duct stones in Billroth II anatomy are limited. The aims of the study were to evaluate the success of DBE-assisted ERCP in patients with Billroth II gastrectomy and examine the efficacy of EPLBD ( $\geq 10$ $\mathrm{mm}$ ) for the removal of common bile duct stones. Patients and methods: A total of 77 patients with Billroth II gastrectomy in whom standard ERCP had failed underwent DBE-assisted ERCP. DBE success was defined as visualizing the papilla and ERCP success as completing the intended intervention. The clinical results of EPLBD for the removal of common bile duct stones were analyzed.

Results: DBE was successful in 73 of 77 patients (95\%), and ERCP success was achieved in 67 of these 73 (92\%). Therefore, the rate of successful

\section{Introduction}

$\nabla$

Up until approximately the last decade, Billroth II gastectomy was the most common surgically altered anatomy that resulted in challenging endoscopic retrograde cholangiopancreatography (ERCP) procedures. ERCP in such patients is usually performed with a duodenoscope or a standard forward-viewing endoscope. Endoscopic and ERCP challenges in patients with Billroth II gastrectomy include identification of and access to the afferent limb, maneuvering through the often long afferent limb to reach the papilla, cannulation of the native papilla (with or without an elevator), and performing a biliary endoscopic sphincterotomy (BES) in a reversed direction. As a result, the ERCP success rate is lower and the complication rate is higher in such patients than it is in those with a normal gastrointestinal (GI)
DBE-assisted ERCP was $87 \%$ (67 of a total of 77 patients). The reasons for ERCP failure $(n=10)$ included tumor obstruction $(\mathrm{n}=2)$, adhesion obstruction $(\mathrm{n}=2)$, failed cannulation $(\mathrm{n}=3)$, failed stone removal $(n=2)$, and bowel perforation $(n=$ 1). Overall DBE-assisted ERCP complications occurred in 5 of 77 patients (6.5\%). A total of 48 patients (34 male, mean age 75.5 years) with common bile duct stones underwent EPLBD. Complete stone removal in the first session was accomplished in 36 patients (75\%); mechanical lithotripsy was required in 1 patient. EPLBD-related mild perforation occurred in 2 patients (4\%). No acute pancreatitis occurred.

Conclusions: DBE permits therapeutic ERCP in patients who have a difficult Billroth II gastrectomy with a high success rate and acceptable complication rates. EPLBD is effective and safe for the removal of common bile duct stones in patients with Billroth II anatomy.

anatomy. In the literature, the success rate of ERCP in patients with a prior history of Billroth II gastrectomy varies from $68 \%$ to $92 \%$ [1-6]. More importantly, the overall perforation rate reaches $18 \%$, and procedure-related mortality reaches $3.4 \%[1-6]$.

Double-balloon enteroscopy (DBE) was first introduced in 2001 as a novel endoscopic technique that allows examination of the entire small bowel [7]. Diagnostic and therapeutic ERCP procedures in which DBE is used have been successfully applied in patients with surgically altered pancreaticobiliary anatomy (e.g., Billroth II gastrectomy and Roux-en-Y anastomosis) since 2006 [8-12]. Most published series of overtube-assisted enteroscopy ERCP included both patients with Billroth II gastrectomy and patients with RouX-en-Y anastomosis, but the endoscopic outcomes and underlying pathologies differed between these 
Table 1 Double-balloon enteroscope characteristics and compatible ERCP devices used in a study of papillary large-balloon dilation in patients with Billroth II anatomy.

\begin{tabular}{|c|c|c|}
\hline & Long DBE (EN-450 T5/W, Fujifilm Endoscopy) & Short DBE (EC-450 BI5, Fujifilm Endoscopy) \\
\hline Diameter of scope, mm & 9.4 & 9.4 \\
\hline Working length, $\mathrm{cm}$ & 200 & 152 \\
\hline Working channel, mm & 2.8 & 2.8 \\
\hline Overtube diameter, mm & 13.2 & 13.2 \\
\hline Overtube length, $\mathrm{cm}$ & 145 & 105 \\
\hline Cannula & Glo-Tip catheter, $320 \mathrm{~cm}$ (Cook) & Glo-Tip catheter, $200 \mathrm{~cm}$ (Cook) \\
\hline Guidewire & Axcess 21 wire, $A X-21-650 E, 650 \mathrm{~cm}$ (Cook) & Jagwire, $450 \mathrm{~cm}$ (Boston Scientific) \\
\hline EPBD balloon & CRE balloon, multiple sizes (Boston Scientific) & CRE balloon, multiple sizes (Boston Scientific) \\
\hline Sphincterotome & NA & Autotome (Boston Scientific) \\
\hline Extraction balloon & ESCORT II balloon, EBL-18 - 320E, 320 cm (Cook) & Extractor Pro Rx Retrieval Balloon (Boston Scientific) \\
\hline Retrieval basket & NA & Dormia basket (Olympus) \\
\hline Mechanical lithotriptor & NA & BML-4Q-1 (Olympus) \\
\hline Biliary plastic stent & Geenen stent, 7 Fr (Cook) & Geenen stent, $7 \mathrm{Fr}$ (Cook) \\
\hline Biliary metal stent & NA & Wallstent (Boston Scientific) \\
\hline Pancreatic stent & Geenen stent, 7 Fr (Cook) & Geenen stent, $7 \mathrm{Fr}$ (Cook) \\
\hline Biopsy forceps & FTE-Biopsy forceps, $250 \mathrm{~cm}$ (Fujifilm Endoscopy) & FTE-Biopsy forceps, $250 \mathrm{~cm}$ (Fujifilm Endoscopy) \\
\hline
\end{tabular}

$\mathrm{DBE}$, double-balloon enteroscope; EPBD, endoscopic papillary balloon dilation.

two entities [13]. A large series of DBE-assisted ERCP focusing on patients with Billroth II gastrectomy was therefore needed.

Bile duct stones are routinely removed at the time of ERCP after BES with a standard balloon or basket extraction technique. However, bile duct stones in patients with Billroth II gastrectomy are difficult to remove because of the challenging access to the bile duct and the inverted direction in which BES must be performed. Traditional techniques for enlarging the biliary orifice to facilitate the removal of such stones require (1) the use of a reversed-angle biliary sphincterotome or (2) the placement of a biliary stent followed by needle-knife sphincterotomy over the stent and supplemental endoscopic papillary balloon dilation (EPBD) of the biliary orifice when large stones are encountered [14].

The efficacy and safety of endoscopic papillary large-balloon dilation (EPLBD; $\geq 10$ - to 12-mm balloon) without preceding BES for the removal of common bile duct stones in normal GI anatomy have been reported in several retrospective studies [15-18]. One small prospective randomized controlled study demonstrated comparable rates of successful stone clearance and complications between EPLBD and BES in patients with normal GI anatomy [19]. A subsequent meta-analysis confirmed that the efficacy and safety of EPLBD alone and BES plus EPLBD for the removal of bile duct stones were similar [20]. The feasibility, efficacy, and safety of EPLBD alone for the removal of bile duct stones by DBEassisted ERCP in patients with Billroth II gastrectomy have not been reported.

The primary objective of our study was to evaluate the success of DBE-assisted ERCP in patients with Billroth II gastrectomy. The secondary objective was to examine the efficacy and safety of EPLBD alone for the removal of difficult bile duct stones in Billroth II anatomy.

\section{Patients and methods \\ $\nabla$}

We reviewed the endoscopic database at Chang Gung Memorial Hospital from April 2006, when DBE (EN-450 T5/W, EC-450 BI5; Fujifilm Endoscopy, Omiya, Japan) was first launched at the institution, to the end of the study period in December of 2013 for patients with Billroth II gastrectomy undergoing enteroscopy with the intent of performing ERCP. The long DBE (EN-450 T5/W) was applied until June 2007, when the short DBE (EC-450 BI5) became available in our institution. The study was approved by the institutional review board of Chang Gung Memorial Hospital. Patients underwent DBE-assisted ERCP after a traditional sideviewing duodenoscope (JF-260; Olympus Optical, Tokyo, Japan) and a forward-viewing upper endoscope (GIF-Q260; Olympus Optical) had failed to enter the afferent limb or reach the major papilla. Reports of six patients who participated in this study were previously published [9]. The database information included patient demographics, symptoms, procedure indications, surgical anatomy, results of noninvasive imaging, prior ERCP attempts, type of sedation, ERCP accessories used, intended duct opacification, endoscopic and radiographic findings, interventions, completion of the intended intervention, reasons for failure, diagnoses, complications, and follow-up, which included subsequent DBE-assisted ERCP, percutaneous trans-hepatic cholangiography, surgery, and assessment of clinical response. The DBE used in the study has a 2.8-mm working channel, which limits the size of devices that can be used to less than $8.5 \mathrm{Fr}$. Characteristics of the long and short DBE devices and the compatible ERCP accessories used in this study are listed in $\bullet$ Table 1.

\section{Endoscopic papillary large-balloon dilation procedures}

After successful selective biliary cannulation, cholangiography was performed to confirm the existence of common bile duct stones. After a guidewire had been inserted into the bile duct, a dilation balloon (CRE balloon, $55 \mathrm{~mm}$ in length, $8-10 \mathrm{~mm} / 10-$ $12 \mathrm{~mm} / 12-15 \mathrm{~mm} / 15-20 \mathrm{~mm}$ in diameter; Boston Scientific, Natick, Massachusetts, USA) was positioned across the major papilla with the mid-portion of the balloon placed at the biliary orifice. Under fluoroscopic guidance, the EPBD balloon diameter was selected according to the size of the stones and bile duct proximal to the tapered segment. Under fluoroscopic and endoscopic guidance, the balloon was gradually inflated with dilute contrast medium until the waist of the balloon had disappeared. Thereafter, the pressure for inflating the balloon was gradually increased until the desired diameter was achieved. Then the pressure was maintained for 3 to 5 minutes based on a previous study [16]. After removal of the balloon, bile duct stones were ex- 
tracted with a retrieval balloon or basket. A mechanical lithotriptor (BML-4Q-1, Olympus) was used to fragment the stones when standard methods failed to remove them. Those patients in whom stone clearance was incomplete had a plastic stent placed to ensure biliary drainage, and a second attempt at stone extraction was performed within 1 month.

\section{Definitions}

The success of DBE-assisted ERCP was defined as in previous studies [21]. DBE success was defined as viewing the papilla. ERCP success was defined as completion of the intended ERCP intervention. Clinical success was defined as more than a 50\% reduction in preprocedural abdominal pain, a $50 \%$ reduction in hepatic enzyme levels if they were elevated, resolution of cholangitis if it was present, and/or complete extraction of bile duct stones if they existed. EPLBD was defined as $10-\mathrm{mm}$ or greater biliary orifice balloon dilation. Adverse events were categorized by using ERCP consensus guidelines [22] and also included other adverse events that could be attributed specifically to enteroscopy, such as peritoneal perforation, dysphagia, and/or odynophagia requiring clinical follow-up.

\section{Results}

\section{$\nabla$}

\section{Overall double-balloon enteroscopy-assisted ERCP re-}

\section{sults}

From April 2006 to December 2013, 77 patients (59 men, 18 women; mean age $73.5 \pm 9.7$, range 50-95) underwent 92 DBEassisted ERCP sessions. Of these, 24 patients (31\%) had a past history of 2 or more abdominal surgeries. Procedure indications included cholangitis ( $n=43$ ), bile duct stones $(n=9)$, malignant bile duct obstruction ( $n=11)$, pancreatitis $(n=6)$, abnormal liver enzyme levels associated with either abdominal pain or dilated bile duct on noninvasive imaging $(n=6)$, and dilated bile duct alone on imaging $(n=2)$. General anesthesia was used in 13 of 92 examinations $(14 \%)$, and conscious sedation with meperidine and midazolam was provided for the rest of the studies. The median procedure time was 80 minutes (range $60-120$ minutes). Long DBE was applied in the first 6 patients (6 ERCP sessions) and short DBE was used for the remaining 71 patients (86 ERCP sessions). Mixed results of long and short DBE-assisted ERCP were presented. DBE success was achieved in 73 of the 77 patients (95\%), and 67 of these 73 patients (92\%) had ERCP success. By intention-to-treat analysis, 67 of 77 patients $(87 \%$ ) had DBE-assisted ERCP success. Among the 73 patients with DBE success, 1 patient had peri-ampullary tumor and biliary cannulation failed. Of the remaining 72 patients with a native papilla, 69 had successful biliary cannulation (96\%) and 67 achieved ERCP success (93\%); 5
Table 2 Double-balloon enteroscopy-assisted ERCP interventions ( $n=171$ ).

\begin{tabular}{|lc|}
\hline Intervention & n \\
\hline Endoscopic papillary balloon dilation & 76 \\
\hline Common bile duct stone extraction & 57 \\
\hline Biliary stenting (7 with metal stent) & 19 \\
\hline Pancreatic stenting & 1 \\
\hline Nasobiliary drainage & 6 \\
\hline Precut needle-knife papillotomy, freehand & 5 \\
\hline Rendezvous cannulation & 3 \\
\hline Tumor sampling & 4 \\
\hline Total & 171 \\
\hline
\end{tabular}

ERCP, endoscopic retrograde cholangiopancreatography.

of the 69 (7\%) required precut needle-knife papillotomy and 3 of the $69(4 \%)$ required percutaneous trans-hepatic cholangiography rendezvous technique to achieve biliary cannulation. DBEassisted ERCP was repeated in 15 patients to complete bile duct stone clearance.

Therapeutic interventions were performed in 68 of the 69 patients $(\bullet$ Table 2$)$. The primary diagnoses in the patients with successful biliary cannulation were bile duct stone $(n=49)$, cystic duct stone with Mirrizzi syndrome ( $n=1)$, malignant biliary stricture $(n=9)$, and biliary dilation alone $(n=9)$.

The primary reason for DBE-assisted ERCP failure $(n=10)$ was failure to reach the papilla $(n=4) ; 2$ of these patients had tumor obstruction within the afferent limb and the other 2 had peritoneal adhesion. The secondary reasons were failed cannulation of a native papilla $(\mathrm{n}=2)$ and failure to remove bile duct stone completely $(n=2)$. Other reasons included peri-ampullary tumor preventing successful cannulation $(\mathrm{n}=1)$ and enteroscope-related intestinal perforation $(n=1)$.

Procedural complications developed in 5 of 77 patients (6.5\%) and included EPBD-related minor perforation $(n=2)$, enteroscope/overtube-related intestinal mucosal tear $(n=2)$, and enteroscope/overtube-related intestinal perforation $(n=1)$. No pancreatitis or bleeding was noted. Most complications were treated nonoperatively $(n=4)$. Surgical intervention was required in 1 patient with afferent limb perforation, and severe adhesions were found during the operation. No mortality related to DBE-assisted ERCP occurred.

Of the 68 patients who underwent therapeutic ERCP, clinical success per protocol was achieved in 66 patients (97\%). Operative intervention was required in 2 patients because of large bile duct stone. Clinical follow-up of more than 3 months was obtained in the majority of those patients who had clinical success (49/66, 74 $\%$ ), with a mean time of 28 months (range 5-92 months). During follow-up, recurrence developed in 6 patients (12\%), which included recurrent common bile duct stones $(n=4)$, acute calculous

Table 3 Comparison of results of double-balloon enteroscopy-assisted ERCP in series of patients with Billroth II gastrectomy.

\begin{tabular}{|c|c|c|c|c|c|c|c|c|}
\hline $\begin{array}{l}\text { Study, first } \\
\text { author }\end{array}$ & $\begin{array}{l}\text { Patients, } \\
\text { n }\end{array}$ & $\begin{array}{l}\text { ERCPs, } \\
\mathbf{n}\end{array}$ & $\begin{array}{l}\text { Mean age, } \\
\text { y }\end{array}$ & $\begin{array}{l}\text { DBE success } \\
\text { rate }\end{array}$ & $\begin{array}{l}\text { ERCP success } \\
\text { rate }\end{array}$ & $\begin{array}{l}\text { Overall } \\
\text { complication } \\
\text { rate }\end{array}$ & $\begin{array}{l}\text { DBE-related } \\
\text { perforation } \\
\text { rate }\end{array}$ & $\begin{array}{l}\text { EPBD-related } \\
\text { perforation } \\
\text { rate }\end{array}$ \\
\hline Shimatani [10] & 17 & 22 & NA & $100 \%$ & $100 \%$ & $0 \%$ & $0 \%$ & $0 \%$ \\
\hline Cho [11] & 6 & NA & NA & $100 \%$ & NA & $0 \%$ & $0 \%$ & $0 \%$ \\
\hline Osoegawa [12] & 15 & 19 & NA & $\begin{array}{c}95 \% \\
(18 / 19)\end{array}$ & $\begin{array}{c}84 \% \\
(16 / 19)\end{array}$ & $\begin{array}{l}5.3 \% \\
(1 / 19)\end{array}$ & $\begin{array}{l}5.3 \% \\
(1 / 19)\end{array}$ & $0 \%$ \\
\hline Present study & 77 & 92 & 73.5 & $\begin{array}{c}95 \% \\
(73 / 77)\end{array}$ & $\begin{array}{c}87 \% \\
(67 / 77)\end{array}$ & $\begin{array}{l}6.5 \% \\
(5 / 77)\end{array}$ & $\begin{array}{l}1.3 \% \\
(1 / 77)\end{array}$ & $\begin{array}{l}2.6 \% \\
(2 / 77)\end{array}$ \\
\hline
\end{tabular}

ERCP, endoscopic retrograde cholangiopancreatography; DBE, double-balloon enteroscopy; EPBD, endoscopic papillary balloon dilation; NA, not available. 


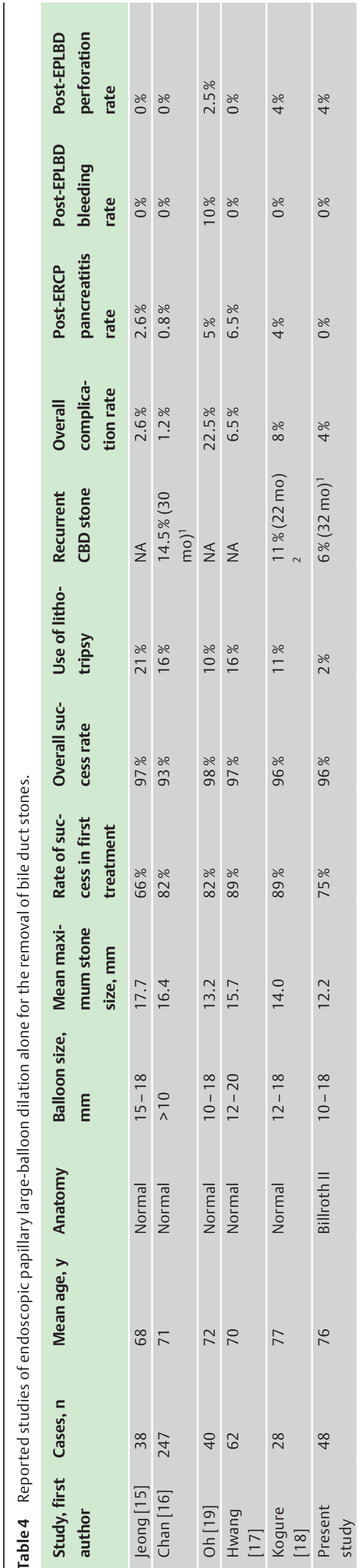

cholecystitis $(\mathrm{n}=1)$, and debris obstruction within a biliary metal stent $(\mathrm{n}=1)$. An additional 4 DBE-assisted ERCPs were performed uneventfully.

The reported success and complicated rates in DBE-assisted ERCP series are summarized in $\bullet$ Table 3.

\section{Endoscopic papillary large-balloon dilation for the removal of bile duct stones}

All patients who had bile duct stones $(n=49)$ were treated with EPBD alone without sphincterotomy. EPBD with an 8-mm balloon was performed in 1 patient, who was excluded from analysis. A total of 48 patients ( 14 women; mean age 75.5 , range $54-$ 95) with bile duct stones who underwent 53 EPLBDs and 60 DBEassisted ERCPs were identified. All patients had a native papilla. Needle-knife precut was required in 3 patients to aid biliary cannulation. Percutaneous trans-hepatic cholangiography rendezvous technique was applied in another 3 patients to gain biliary access. A prophylactic pancreatic stent was placed in 1 patient because of difficult cannulation.

The mean maximum transverse diameter of the largest stone was $12.2 \mathrm{~mm}$ (range $6-35 \mathrm{~mm}$ ), and the mean number of bile duct stones was 3 (range $1-8$ ). The mean maximum diameter of distal bile duct was $15.7 \mathrm{~mm}$ (range $9-35 \mathrm{~mm}$ ). The mean size of the dilating balloon was $13.1 \mathrm{~mm}$ (range $10-18 \mathrm{~mm}$ ). Complete clearance of the bile duct stones in $1 \mathrm{DBE}$-assisted ERCP session was achieved in 36 patients (75\%). In an additional 10 patients (21 $\%)$, stones were successfully extracted in the second session. Mechanical lithotripsy was used in 1 patient (2\%). Failure of stone clearance occurred in 2 patients (4\%), both with a very large stone size $(30 \mathrm{~mm}$ and $35 \mathrm{~mm})$. These 2 patients had a biliary stent placed to ensure biliary drainage and underwent surgical intervention.

Short-term complications were documented in 2 patients (4\%), in whom mild papillary perforation developed after EPLBD with a 12-mm CRE balloon (patient had a maximum stone size of 16 $\mathrm{mm}$, maximum common bile duct caliber of $15 \mathrm{~mm}$, and distal common bile duct caliber of $12 \mathrm{~mm}$ ) and after EPLBD with an 18-mm CRE balloon (patient had a maximum stone size of 30 $\mathrm{mm}$, maximum common bile duct caliber of $35 \mathrm{~mm}$, and distal common bile duct caliber of $18 \mathrm{~mm}$ ). Both complications were identified during ERCP procedures and treated uneventfully by endoscopic nasobiliary drainage and conservative management. No procedure-related bleeding or pancreatitis was documented. Long-term ( $\geq 6$-month) follow-up data were available in 35 of 46 patients $(76 \%)$ with complete removal of bile duct stones. The mean follow-up period was 32 months (range 6-92 months). During follow-up, 2 patients (5.7\%) developed recurrent bile duct stones, which were successfully retrieved by DBE-assisted ERCP and EPLBD. Another patient developed acute calculous cholecystitis 2 years after ERCP and underwent cholecystectomy. The reported success and complication rates with EPLBD alone for the removal of bile duct stones are summarized in $\bullet$ Table 4 .

\section{Discussion}

Since the first introduction of DBE-assisted ERCP in patients with surgically altered GI anatomy in 2006 [8], many related studies have been published. However, most of the studies included patients with Billroth II gastrectomy and a variety of Roux-en-Y altered anatomies. The indications, procedural difficulties, and treatment outcomes of DBE-assisted ERCP for Billroth II surgery 
and those for Roux-en-Y surgery are different. One systematic review showed that the overall endoscopic and ERCP success rates of overtube-assisted enteroscopy ERCP were highest in patients with Billroth II anatomy, next-highest in those with pancreaticoduodenectomy and Roux-en-Y hepaticojejunostomy, and lowest in patients with Roux-en-Y gastric bypass (endoscopic success rates of $96 \%$ vs. $85 \%$ vs. $80 \%$; ERCP success rates of $90 \%$ vs. $76 \%$ vs. $70 \%$, respectively) [13]. The overall major complication rate of overtube-assisted enteroscopy ERCP was 3.4\%. In this study, we present our experience of DBE-assisted ERCP in a large cohort of patients with Billroth II gastrectomy. Our patients $(n=77)$ outnumbered those analyzed in the review article $(n=57)$, and the results showed a DBE success rate of $95 \%$ and an ERCP success rate of $87 \%$, which were comparable with those of the published meta-analysis.

The endoscopic management of patients who have undergone Billroth II gastrectomy is challenging because of the altered anatomical features and postoperative adhesions. The challenges to successful ERCP include difficulty in inserting an endoscope deeply into the afferent loop, in inserting a catheter deeply and selectively into the bile duct, and in performing therapeutic procedures safely. Although patients with Billroth II gastrectomy can undergo ERCP with a standard duodenoscope or forward-viewing endoscope, the endoscopic approach to the afferent loop and blind end is difficult in patients with severe adhesions or a long afferent loop.DBE-assisted ERCP has been shown to be a minimally invasive alternative to percutaneous trans-hepatic cholangiography and surgery, with an acceptable risk profile in previous studies [10-12]. The reported success and complication rates of DBE-assisted ERCP in various series are summarized in $\bullet$ Table 3. A single-balloon overtube-assisted enteroscopy system has demonstrated similar results in patients with Billroth II gastrectomy [23].

During Billroth II surgery, the proximal gastric stump is anastomosed in an end-to-side fashion with a loop of jejunum. The afferent side of the loop is at a variable distance from the ligament of Treitz and can be as short as $30 \mathrm{~cm}$ in a retrocolic anastomosis but longer than $80 \mathrm{~cm}$ in an antecolic configuration. Most of our patients had undergone antecolic, antiperistaltic reconstruction, and the identification and intubation of the afferent limb were thus more difficult. In our previous study, ERCP success with a duodenoscope was accomplished in $70 \%$ of these patients, and the reasons for ERCP failure included a sharp gastrojejunal anastomosis curve (6\%), a long afferent loop (19\%), and duodenoscope-related bowel perforation (6\%) [9]. Advancement of the DBE into the afferent limb of a Billroth II anastomosis is easier, given the short radius of curvature of the tip of the scope. The DBE system has two balloons at the tip of the enteroscope and overtube, which allow the endoscopist to hold the intestine and insert the enteroscope deeply while shortening the intestine simultaneously. The push-and-pull manipulation helps overcome and shorten the tortuous and long afferent loop. In the current study, the DBE successfully reached the papilla in $95 \%$ of the patients in whom the journey could not be completed with a standard method. Instrument-related complications occurred in 3 patients and included 2 intestinal mucosal tears and 1 perforation. Comparisons between our study and published ERCP series of patients with Billroth II gastrectomy in whom a standard method was used are summarized in $\bullet$ Table 5.

Once the papilla has been reached, cannulation of the intact papilla with a forward-viewing enteroscope is associated with two challenges in orientation-namely, working without an elevator 
and approaching with a forward rather than a side view. Furthermore, proper ERCP accessories should be chosen for different versions of the DBE. Standard accessories can be applied to the short DBE system (EC-450 BI5); however, specialized accessories are needed for the long DBE (EN-450 T5), as shown in 0 Table 1. In our experience, a short DBE system can complete ERCP in all patients with Billroth II gastrectomy and most patients with Rouxen-Y anastomosis. Given the lack of an elevator, papillary cannulation is best achieved with a straight catheter and a guidewire. Manipulation of both the overtube and the enteroscope makes it possible to change the position of the papilla and to align the axes of a cannula and the bile duct. Despite the unfavorable factors for cannulation, when the papilla is reached by DBE, the ERCP technical success rates approached those seen in patients with intact GI anatomy [10, 21]. In our study, ERCP success was obtained in $92 \%$ of the patients in whom the major papilla was accessed by DBE.

Choledocholithiasis was the major final diagnosis in our series, and 49 of 69 patients (71\%) with successful biliary cannulation underwent stone removal. Traditional BES in patients with Billroth II gastrectomy is achieved with the use of a reversed-angle sphincterotome or with placement of a stent followed by needle-knife sphincterotomy over the stent. However, the size of the sphincterotomy is reduced because of poor handling of the accessories and poor visualization of the upper margin of the papilla roof secondary to its inverted location. Therefore, BES may be ineffective for the removal of large bile duct stones. Furthermore, BES in patients with Billroth II gastrectomy is associated with an increased risk of bleeding and perforation.

Alternatively, EPLBD after a partial BES is an acceptable option for the removal of larger stones with minimized risk in patients who have Billroth II gastrectomy. The safety and efficacy of BES followed by EPLBD have been demonstrated in several ERCP series of patients with normal anatomy [24-26]. The reported rates of successful stone removal ranged from $89 \%$ to $100 \%$, rates of mechanical lithotripsy use from $1 \%$ to $29 \%$, overall complication rates from $4 \%$ to $15.5 \%$, and post-ERCP pancreatitis rates from $0 \%$ to $8 \%$. Most reported cases of pancreatitis were mild. In a multicenter U.S.study, Attasaranya et al. reported the use of BES followed by EPLBD $(\geq 12 \mathrm{~mm})$ and the selective use of mechanical lithotripsy as an effective therapy for the removal of relatively large $(\geq 10 \mathrm{~mm})$ bile duct stones [24]. The authors reported a $95 \%$ complete stone clearance rate in one session with the use of mechanical lithotripsy in $27 \%$ of procedures. Teoh et al. further confirmed that combined BES/EPLBD and BES alone cleared bile duct stones with equal efficacy; however, combined therapy reduced the need for mechanical lithotripsy and the cost of hospitalization [26]. Combined BES/EPLBD therapy was applied to ERCP in patients with Billroth II gastrectomy with similar yields. Choi et al. reported a $100 \%$ rate of stone removal and no complications with combined BES and EPLBD (10 - to 15-mm balloon) in 26 patients with Billroth II gastrectomy [14]. Mechanical lithotripsy was required in $12 \%$ of these patients.

Contrary to the consistent findings of safety and efficacy with combined BES/EPLBD therapy, controversy remains regarding EPBD without preceding BES for the removal of bile duct stones. EPBD alone possesses the advantage of technical ease and less bleeding. EPBD with a small balloon appears to preserve partial function of the sphincter of Oddi over the medium term [27]. However, several prospective studies comparing small-diameter $\operatorname{EPBD}(\leq 8 \mathrm{~mm})$ and BES for the removal of bile duct stones reported a post-EPBD pancreatitis rate of $7 \%$ to $15 \%$ [ $28-30]$. One pro- spective randomized multicenter U.S. study showed a significantly higher overall complication rate in the small-diameter EPBD group than in the BES group (17.9\% vs. $3.3 \%$ ), in addition to a higher acute pancreatitis rate ( $15.4 \%$ vs. $0.8 \%$ ), including 2 deaths from severe pancreatitis in the EPBD group [30]. The authors claimed that the post-ERCP pancreatitis was probably due to edematous change or trauma after the dilation procedure, resulting in obstruction of the pancreatic duct. However, recent studies (all from Asia) reported that EPLBD alone $(\geq 10-12 \mathrm{~mm})$ can have a high rate of successful stone clearance, with fewer complications (including pancreatitis), and can minimize the use of mechanical lithotripsy [15-19]. The efficacy and safety profile of EPLBD alone in published series, shown in $\bullet$ Table 4, is similar to that of the aforementioned combined BES/EPLBD method.

The discrepancy between the treatment outcomes of small- and large-diameter EPBD is probably related to the "created size" of the biliary orifice rather than to the dilation procedure itself. EPBD with a small balloon requires the addition of laborious procedures that are traumatic to the papilla, such as mechanical lithotripsy, to remove large stones successfully, which can lead to the development of complications like pancreatitis and cholangitis. Large-balloon dilation results in the permanent loss of sphincter function and a large biliary opening, which can prevent accidental cannulation of the pancreatic duct during the subsequent stone extraction and stone impaction in the common duct. Consequently, there is less need to apply mechanical lithotripsy than in small-diameter EPBD. Thus, the main purpose of EPLBD in endotherapy is to avoid additive therapeutic procedures, simplify the process of stone extraction, and reduce the complication rate. Simplifying treatment procedures while maintaining the efficacy of stone removal is especially important in the removal of difficult bile duct stones, such as those in patients with Billroth II gastrectomy. Itoi et al. reported that combined BES/EPLBD therapy reduced ERCP procedure time and fluoroscopy time in comparison with BES alone [25].

A unique feature of our series is that it is the first report of patients with Billroth II gastrectomy and bile duct stones undergoing both DBE-assisted ERCP and therapy with EPLBD alone. We found that the success rate of bile duct clearance after EPLBD was high, although additional sessions may be needed to secure the result. The adverse events of EPLBD in these patients are acceptable. Although combined BES and EPLBD therapy is safe and effective in treating patients with Billroth II anatomy and bile duct stones, we cannot provide such information because of the study design. The other limitation of our study is the retrospective analysis, which may have contributed to an underestimation of the complication rate. In addition, many older patients were included in this study, whose risk of post-ERCP pancreatitis may be small.

In conclusion, our investigation suggests that ERCP is successful in a majority of patients with Billroth II gastrectomy when an advanced overtube-assisted DBE technique is performed at a tertiary care center. EPLBD can be performed with equal efficacy and safety in patients with Billroth II gastrectomy. Given the acceptable risk profile and long-term follow-up results, DBE-assisted ERCP should be considered as an alternate therapy when traditional ERCP has failed, and EPLBD as a standard therapy for difficult bile duct stones in patients with Billroth II gastrectomy.

\section{Competing interests: None}


Institutions

${ }^{1}$ Division of Gastroenterology, Department of Medicine, Chang Gung Memorial Hospital and Chang Gung University, Taoyuan, Taiwan

2 Division of General Surgery, Department of Surgery, Chang Gung Memorial Hospital and Chang Gung University, Taoyuan, Taiwan

\section{Acknowledgment}

The authors thank Stuart Sherman, MD, and Glen A. Lehman, MD, of Indiana University Medical Center, Indianapolis, Indiana, USA, for their review and comments during the preparation of this article.

\section{References}

$1 \mathrm{Kim} \mathrm{MH}$, Lee SK, Lee $\mathrm{MH}$ et al. Endoscopic retrograde cholangiopancreatography and needle-knife sphincterotomy in patients with Billroth II gastrectomy: a comparative study of the forward-viewing endoscope and the side-viewing duodenoscope. Endoscopy 1997; 29: $82-$ 85

2 Faylona JMV, Qadir A, Chan ACW et al. Small-bowel perforations related to endoscopic retrograde cholangiopancreatography (ERCP) in patients with Billroth II gastrectomy. Endoscopy 1999; 31: 546 -549

3 Swarnkar K, Stamatakis JD, Young WT. Diagnostic and therapeutic endoscopic retrograde cholangiopancreaticography after Billroth II gastrectomy - safe provision in a district general hospital. Ann R Coll Surg Engl 2005; 87: 274-276

4 Ciçek B, Parlak E, Disibeyaz S et al. Endoscopic retrograde cholangiopancreatography in patients with Billroth II gastroenterostomy. J Gastroenterol Hepatol 2007; 22: 1210-1213

5 Lin LF, Siauw CP, Ho KS et al. ERCP in post-Billroth II gastrectomy patients: emphasis on technique. Am J Gastroenterol 1999; 94: 144-148

6 Byun JW, Kim JW, Sung SY et al. Usefulness of forward-viewing endoscope for endoscopic retrograde cholangiopancreatography in patients with Billroth II gastrectomy. Clin Endosc 2012; 45: 397-403

7 Yamamoto H, Sekine Y, Sato Y et al. Total enteroscopy with a nonsurgical steerable double-balloon method. Gastrointest Endosc 2001; 53 : 216-220

8 Mehdizadeh S, Ross A, Gerson L et al. What is the learning curve associated with double-balloon enteroscopy? Technical details and early experience in 6 US tertiary care centers Gastrointest Endosc 2006; 64: $740-750$

9 Lin CH, Tang JH, Cheng CL et al. Double balloon endoscopy increases the ERCP success rate in patients with a history of Billroth II gastrectomy. World J Gastroenterol 2010; 16: 4594-4598

10 Shimatani M, Matsushita M, Takaoka M et al. Effective "short" doubleballoon enteroscope for diagnostic and therapeutic ERCP in patients with altered gastrointestinal anatomy: a large case series. Endoscopy 2009; 41: 849-854

11 Cho S, Kamalaporn P, Kandel G et al. 'Short' double-balloon enteroscope for endoscopic retrograde cholangiopancreatography in patients with a surgically altered upper gastrointestinal tract. Can J Gastroenterol 2011; 25: 615-619

12 Osoegawa T, Motomura $Y$, Akahoshi $K$ et al. Improved techniques for double-balloon enteroscopy-assisted endoscopic retrograde cholangiopancreatography. World J Gastroenterol 2012; 18: 6843-6849

13 Skinner M, Popa D, Neumann $H$ et al. ERCP with the overtube-assisted enteroscopy technique: a systemic review. Endoscopy 2014; 40: 560 572
14 Choi CW, Choi JS, Kang DH et al. Endoscopic papillary large balloon dilation in Billroth II gastrectomy patients with bile duct stones. J Gastroenterol Hepatol 2012; 27: 256-260

15 Jeong S, Ki SH, Lee $\mathrm{OH}$ et al. Endoscopic large-balloon sphincteroplasty without preceding sphincterotomy for the removal of large bile duct stones: a preliminary study. Gastrointest Endosc 2009; 70: 915-922

16 Chan HH, Lai KH, Lin CK et al. Endoscopic papillary large balloon dilation alone without sphincterotomy for the treatment of large bile duct stones. BMC Gastroenterol 2011; 11: 69

17 Hwang JC, Kim JH, Lim SG et al. Endoscopic large-balloon dilation alone versus endoscopic sphincterotomy plus large-balloon dilation for the treatment of large bile duct stones. BMC Gastroenterol 2013; 13: 15

18 Kogure H, Tsujino T, Isayama $H$ et al. Short- and long-term outcomes of endoscopic papillary large balloon dilation with or without sphincterotomy for removal of large bile duct stones. Scand J Gastroenterol 2014; 49: $121-128$

19 Oh MJ, Kim TN. Prospective comparative study of endoscopic papillary large balloon dilation and endoscopic sphincterotomy for removal of large bile duct stones in patients above 45 years of age. Scand J Gastroenterol 2012; 47: $1071-1077$

$20 \mathrm{Kim} \mathrm{JH,} \mathrm{Yang} \mathrm{MJ,} \mathrm{Hwang} \mathrm{JC} \mathrm{et} \mathrm{al.} \mathrm{Endoscopic} \mathrm{papillary} \mathrm{large} \mathrm{balloon} \mathrm{di-}$ lation for the removal of bile duct stones. World J Gastroenterol 2013; 19: $8580-8594$

21 Shah RJ, Smolkin M, Yen R et al. A multicenter U.S. experience of singleballoon, double-balloon, and rotational overtube-assisted enteroscopy ERCP in patients with surgically altered pancreaticobiliary anatomy (with video). Gastrointest Endosc 2013; 77: 593-600

22 Cotton PB, Lehman G, Vennes J et al. Endoscopic sphincterotomy complications and their management: an attempt to consensus. Gastrointest Endosc 1991; 37: 383-393

23 Itoi T, Ishii K, Sofuni A et al. Single-balloon enteroscopy-assisted ERCP in patients with Billroth II gastrectomy or Roux-en-Y anastomosis (with video). Am J Gastroenterol 2010; 105: 93 -99

24 Attasaranya S, Cheon YK, Vittal $\mathrm{H}$ et al. Large-diameter biliary orifice balloon dilation to aid in endoscopic bile duct stone removal: a multicenter series. Gastrointest Endosc 2008; 67: 1046-1052

25 Itoi T, Itokawa F, Sofuni A et al. Endoscopic sphincterotomy combined with large balloon dilation can reduce the procedure time and fluoroscopy time for removal of large bile duct stones. Am J Gastroenterol 2009; 104: 560-565

26 Teoh AYB, Cheung FKY, Hu B et al. Randomized trial of endoscopic sphincterotomy with balloon dilation versus endoscopic sphincterotomy alone for removal of bile duct stones. Gastroenterology 2013; 144: $341-345$

27 Yasuda I, Tomita E, Enya M et al. Can endoscopic papillary balloon dilation really preserve sphincter of Oddi function? Gut 2001; 49: 686691

28 Bergman JJ, Rauws EA, Fockens P et al. Randomized trial of endoscopic balloon dilation versus endoscopic sphincterotomy for removal of bile duct stones. Lancet 1997; 349: 1124-1129

29 Fujita N, Maguchi H, Komatsu $Y$ et al. Endoscopic sphincterotomy and endoscopic papillary balloon dilatation for bile duct stones: a prospective randomized controlled multicenter trial. Gastrointest Endosc 2003; $57:$ 151- 155

30 DiSario JA, Freeman ML, Bjorkman DJ et al. Endoscopic balloon dilation compared with sphincterotomy for extraction of bile duct stones. Gastroenterology 2004; 127: 1291 - 1299 